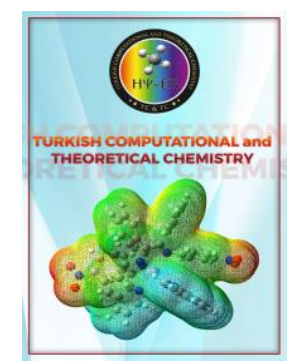

Received: 11.10 .2018
Turkish Computational and Theoretical Chemistry

Turkish Comp Theo Chem (TC\&TC)

Volume(Issue): 3(2) - Year: 2019 - Pages: 69-75

ISSN: 2587-1722 / e-ISSN: 2602-3237

https://doi.org/10.33435/tcandtc.469486

Accepted: 26.02 .2019

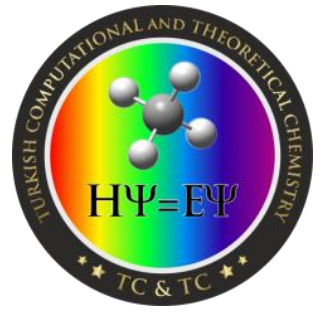

Research Article

\title{
Optimization and Mathematical Modelling of Gallic Acid Extraction and Determination of Diffusion Coefficients
}

\author{
Emirhan HESAP ${ }^{1}$, Diclecan BULUT, Sibel YIGITARSLAN \\ Suleyman Demirel University, Engineering Faculty, Department of Chemical Engineering, \\ Isparta/TURKEY
}

\begin{abstract}
Polyphenols, which have attracted attention with their anti-carcinogenic properties in recent years, are used in many fields and are found in many fruits, vegetables and cereals. It has also started to be used industrially in food and pharmaceutical industries. The researches conducting on the kinetics, diffusion coefficient and their relations with temperature, which make the process industrially more efficient, were scarcely available. In this study, total polyphenol extraction from Cinnamonumzeylaniccum with the help of methanol solvent was investigated within this concept. Different parameters were examined including temperature $\left(25-60^{\circ} \mathrm{C}\right)$, time of extraction $(10-90$ minutes), mixing rate $(0-250 \mathrm{rpm})$, and solid-to-liquid ratio $(0.3-1.5 \mathrm{~g} / 40 \mathrm{~mL})$ in the single-optimization method. Multiple optimization parameters were examined and three-dimensional respose surfaces were plotted by Design Expert program according to the optimum results of the single optimization. In the light of this data, it was concluded that the most effective single parameter was the temperature, and the most effective binary parameters were the time-temperature. Diffusion kinetics data were obtained by performing experiments at different temperatures in a stirred and unmixed media. These data were used to determine the molecular, convective and effective diffusion coefficients and to calculate the activation energies. The values of diffusion coefficients were calculated by using Peleg and Mass transfer models, and Arhenius rule was used for determination of activation energies. As a result of the study, molecular, effective and convective diffusion coefficients were determined for three different temperatures, and the activation energies of molecular and convective diffusion were found as 54643.77 $\mathrm{J} / \mathrm{mole}$ and $6326.12 \mathrm{~J} / \mathrm{mole}$, respectively.
\end{abstract}

Keywords: Polyphenols, Modelling, Diffusion, Gallic Acid, Cinnamonum zeylaniccum.

\section{Introduction}

Currently, one of the most common diseases in the world is different types of cancer [1]. The search for different solutions to cancer like usage of herbal remedies has become increasingly important. Polyphenols in medicinal aromatic plants have proven positive effects on human health and are therefore there are several studies focusing on the investigation of the causes, metabolism of different types of cancers and treatment of them with these compounds [2]. The aim of drug release system development for cancer treatment is gaining importance within these studies.

Cinnamon is one of the medicinal aromatic plants and the especially dried husk of the cinnamon tree is used as a spice in general consumption and in daily life. There are about 100 different kinds of cinnamon. The countries that produce the highest amount of cinnamon

\footnotetext{
${ }^{1}$ Corresponding authors

E-mail: emirhanhesap@gmail.com
} 
production in the world are China, Indonesia, and Sri Lanka respectively. This plant is known for its anti-carcinogenic, antiseptic properties, releasing ureteral and kidney stones [3].

Gallic acid, a phenolic flavonoid, has an attractive property such as interacting with cancer cells without interacting with healthy cells $[4,5]$. Gallic acid has been shown to inhibit free radicals and heavy metal ions by forming chelates [6-9]. There are thousands of flavonoids present in nature, and different components are obtained depending on the extraction conditions. Due to the variability of the extraction method, solvent type, temperature, time of diffusion, mixing rate, and the competition between the molecules of the different type of flavonoids, it is almost impossible to determine the most efficient extraction condition without optimizing the process. Therefore, multipleparameter optimization methods have been developed, and the response surface method has been used frequently in those optimization processes [10-14].

Investigation of the kinetics of the extraction of gallic acid from Cinnamonum zeylaniccum, the determination of the constants of this process such as diffusion coefficients and activation energies are not available in the literature. Due to the fact that these data are required in developing drug delivery systems, in order to lead the development of drug delivery system that will be used in gastrointestinal cancer treatments in the future, the purpose of this study was determined as follows: i) to maximize the yield of extraction of gallic acid from the plant by using multiple-optimization methods, ii) to determine the model equation representing the extraction process, and iii) to calculate the specific constants of their diffusion.

\section{Computational Method}

Cinnamonumzeylaniccum was obtained from the herbalist and chemicals such as methanol, Folin-Ciocalteu and sodium carbonate were obtained from Sigma_Aldrich at an analytical purity. In the study, optimization of the extraction process of polyphenols from Cinnamon zeylaniccum in the presence of methanol as solvent was carried out in two steps. In the first step singleparameter optimization was realized with the parameters including temperature $\left(25-60^{\circ} \mathrm{C}\right)$, solidto-liquid ratio $(0.3-1.5 \mathrm{~g} / 40 \mathrm{~mL})$, extraction time
(10-90 minutes), and mixing rate (50-250 rpm). Then, based on the results obtained from the single optimization the most effective three parameters were determined. Afterwards, in multipleoptimization method step, the Response Surface Method based on three-centered three-level BoxBenkhen experimental design was applied with those parameters chosen.

In a single optimization, each value of the parameter to be studied was changed, while other parameters were kept constant. Then the gallic acid amounts obtained at the specific conditions were compared. The highest amount of gallic acid produced condition was chosen as optimum at that parameter studied. Then, other parameters was studied in the same procedure. By this way, the optimum values for each parameter in the single optimization were determined. The most effective three parameters on the extraction yield were used in multiple optimization section.

Table 1. Box-BenkhenExperimental Design parameters and anges

\begin{tabular}{llll}
\hline $\begin{array}{l}\text { Parameters } \\
\text { Solid/liquidratio }\end{array}$ & -1 & 0 & +1 \\
$(\mathrm{~g} / \mathrm{mL})$ & & $0.3 / 35$ & $0.3 / 45$ \\
Temperature $\left({ }^{\circ} \mathrm{C}\right)$ & 50 & 55 & 60 \\
Time $(\min )$ & 75 & 80 & 85 \\
\hline
\end{tabular}

Multiple optimization was performed by using a computer program called Design Expert. According to the results obtained from single optimization, the parameters given in Table 1 were coded as -1 for their minimum values, 0 for their median value and +1 for their maximum value, and then all of them were entered into the program. To express the extraction efficiency, a second order polynomial function given in Equation 1 had been proposed. In Equation 1, y represents the estimated response (extraction efficiency), the term xi represents the effect of the corresponding parameter, the xixj, xjxk, xixk terms express the interactive effects of these parameters, $\beta$ is the coefficient of the respective term, and finally, $\varepsilon$ represents the random error.

$y=\beta_{0}+\sum_{j=1}^{k} \beta_{j} X_{j}+\sum_{j=1}^{k} \beta_{i j} X^{2}{ }_{j}+\sum_{i=1}^{j-1} \sum_{j=2}^{k} \beta_{i j} X_{i} X_{j}+\varepsilon$

Box-Benkhen experiment design parameter ranges, consisting of 15 experimental sets with 3 
central experiments, were calculated according to the change interval of the parameters given in Equation 2 and entered into the program. Then, gallic acid equivalent total flavonoid analyzes were performed on the extracts and the data obtained from the experiments performed under the desired conditions were entered into the computer program. Finally, the three-dimensional graphs, which represent the extraction surface, were plotted after the statistical analyzes were completed. The equations and coefficients that define the surface were determined and the optimum values of each parameter were calculated by numerical optimization.

$x i=\frac{x i-x o}{\Delta x}$

At this stage, in order to determine the model equation of the extraction, and gallic acid diffusion coefficients, according to the results of multiple optimizations and the parameter ranges given in Table 1, the extractions were performed at three different temperatures in two different environments containing mixed and unmixed conditions for 80 minutes. The amount of total flavonoid in the extracts were measured in every 5 minutes, and the results were used examination of the kinetic model expressions.

Mass transfer during extraction generally takes place in two stages; First, the solvent penetrates the solid material to dissolve the material to be extracted, and then the desired material to be extracted passes from the interior of the solid material to the solvent liquid. The rate determining step of this process is called diffusion [15]. Under unsteady-state conditions, this step is defined by the second law of Fick given in Equation 3:

$\frac{\partial c}{\partial t}=D \frac{\partial^{2} c}{\partial x^{2}}$

This equation is applicable when a highly diluted solution is used in the mass transfer during extraction and the diffusivity is assumed to be constant [16]. $\mathrm{x}$ refers to the diffusion distance. When this equation is solved with the assumptions (such as; if the solid parts have perfect sphere and same properties, if the process environment has perfect mixing and if the process time is too long) the general solution will be as follows:
$\operatorname{Ln}\left(\frac{c_{\infty}}{c_{\infty}-c}\right)=0.498+\frac{9.87 D t}{R^{2}}$

In Equation 4, c denotes the concentration of material extracted into the medium at time $\mathrm{t}(\mathrm{mg} / \mathrm{g})$, $\mathrm{c} \infty$ is the concentration of the extracted material at time $\mathrm{t}=\infty$, and $\mathrm{R}$ is the characteristic distance (m). When the equation is edited:

$\operatorname{Ln}\left(\frac{c_{e q}}{c_{e q}-c}\right)=a+K_{o b s} t$

where $\mathrm{c}_{\infty}$ is considered to be the equilibrium concentration and $\mathrm{a}$ is the equilibrium concentration constant that is equal to 0.498 . By applying these into Equation 5:

$K_{\text {obs }}=\frac{9.87 D}{R^{2}}$

In this study, Equation 6 was used to apply experimental data and to obtain Kobs and diffusion coefficient values.

The fitness of all of the models were determined by comparing of their correlation coefficients calculated from Equation 7. In that, yi represents the experimental data and ymodel denotes model prediction value at the same experimental conditions. The higher the correlation constant, the higher the model fitness.

$r^{2}=1-\frac{\sum_{i=1}^{n}\left(y_{i}-y_{\text {model }}\right)^{2}}{\sum_{i=1}^{n}\left(y_{i}-y_{\text {mean }}\right)^{2}}$

In this study, Arrhenius law given in Equation 8 was used to calculate the amount of energy required for extraction of flavonoids from cinnamon.

$k=k_{0} \exp \left(\frac{-E_{a}}{R T}\right)$

Here, $\mathrm{k}$ denotes the extraction rate constant (L/g.min), $\mathrm{k} 0$ is the temperature independent factor (L/g.min), Ea activation energy ( $\mathrm{j} / \mathrm{mol}), \mathrm{R}$ is the universal gas constant $(8.314 \mathrm{j} / \mathrm{mol} . \mathrm{K})$, and $\mathrm{T}$ refers to the absolute temperature of the extraction medium $(\mathrm{K})$. Thus, after the linearization, $\ln \mathrm{k}$ is 
plotted against $1 / \mathrm{T}$. The activation energy and $\mathrm{k} 0$ is determined from equation 9 [17]:

$\operatorname{Ln} k=\operatorname{Ln} k_{0}+\left(\frac{-E_{a}}{R T}\right)$

When extraction was completed at every specified conditions, the samples were obtained by filtering the medium via $110 \mathrm{~mm}$ Whatman filter paper. To determine the total amount of gallic acid equivalent of flavonoids in the extracts, $0.5 \mathrm{~mL}$ of Folin-Ciocalteu, $450 \mu \mathrm{L}$ of distilled water, $1.5 \mathrm{~mL}$ of $\mathrm{Na} 2 \mathrm{CO} 3$ ( $20 \%$ by weight) were added to the $50 \mu \mathrm{L}$ extract sample, and after stirring $5 \mathrm{~mL}$ of distilled water was added. Then, the mixture was incubated in an incubator at $25^{\circ} \mathrm{C}$ for 2 hours. Finally, the mixtures were analyzed by UV_VIS spectrophotometer (Carry 60) at a wavelength of $765 \mathrm{~nm}$ when incubation was complete and the stable color formation was observed. Gallic acid concentrations were calculated by entering the absorbance values into the calibration curve given in equation 10 .

Absorbance $=0.001532 *$ Concentration; $\mathrm{R} 2=0.9174(10)$

\section{Results and Discussion}

In this study, the amounts of gallic acid extracted were compared with the model predictions at the same conditions. Mass transfer model was determined as the best model representing the extraction of gallic acid equivalent of flavonoids from the plant. Extractions at unmixed condition, i.e. molecular diffusions, were shown in Figures 1, 3, and 5; while extractions at mixed mediums, i.e. convective diffusions, were represented in Figures 2, 4, and 6. As it can be seen from the Figures 1-6, the yield of extractions was found increasing as the temperature increases and as the mixing operation was applied to the medium. These findings are in accordance with these wellknown realities: the increase in temperature increases the molecular movement of the extracted material and also increases the solubility of the extract in the solvent, and mixing operation results an increase in interaction of solvent and the material. In the mass transfer model, the optimum conditions for this study were found at $55^{\circ} \mathrm{C}$ in a mixed medium. In addition, experimental and calculated concentration values were observed to be closer together with increasing temperature. The yield decreased as methanol approached to boiling point. Thus, it was concluded that the mass transfer model can be used effectively at high temperatures.

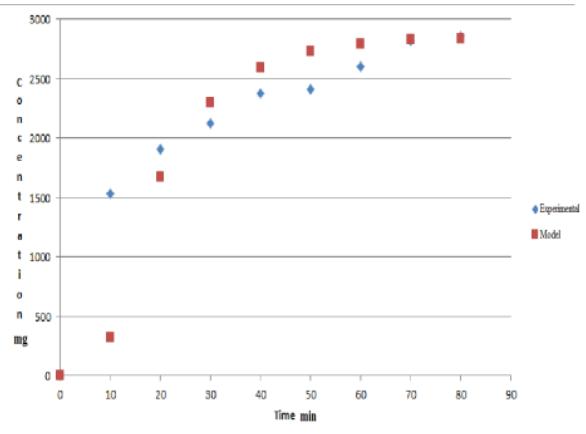

Fig 1. Moleculer diffusion at $50{ }^{\circ} \mathrm{C}$.

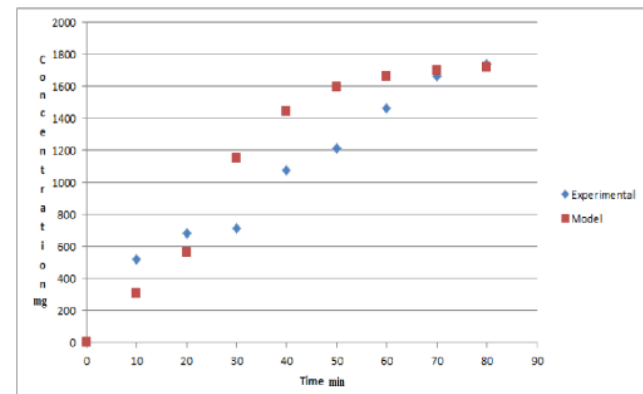

Fig 2. Convectivediffusion at $50^{\circ} \mathrm{C}$.

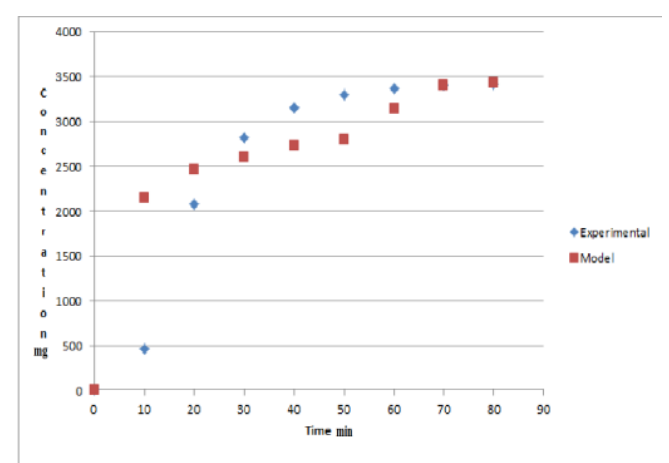

Fig 5.Moleculerdiffusion at $60{ }^{\circ} \mathrm{C}$

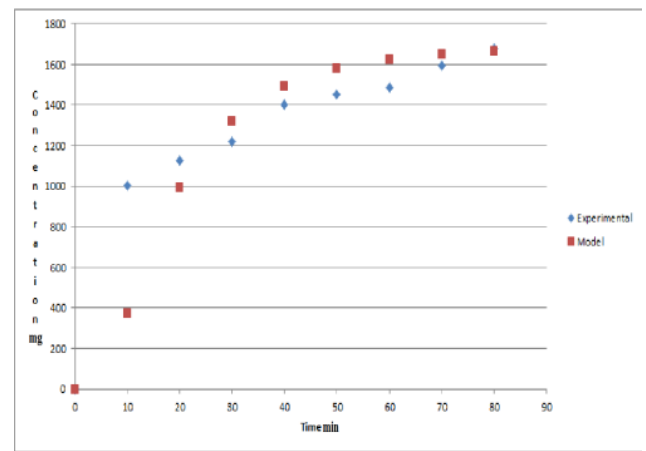

Fig 6. Convectivediffusion at $60{ }^{\circ} \mathrm{C}$. 
Table 2. Diffusion Coefficients at different temperatures

\begin{tabular}{llll}
\hline $\mathrm{T}\left({ }^{\circ} \mathrm{C}\right)$ & $\begin{array}{l}\mathrm{D}_{\text {moleculer }} \\
\left(\mathrm{m}^{2} / \mathrm{s}\right)\end{array}$ & $\begin{array}{l}\mathrm{D}_{\text {convective }} \\
\left(\mathrm{m}^{2} / \mathrm{s}\right)\end{array}$ & $\begin{array}{l}\mathrm{D}_{\text {effective }} \\
\left(\mathrm{m}^{2} / \mathrm{s}\right)\end{array}$ \\
50 & 0.1228 & 0.1737 & 0.2965 \\
55 & 0.1879 & 0.1542 & 0.3421 \\
60 & 0.1543 & 0.1703 & 0.3246 \\
\hline
\end{tabular}

Diffusion coefficients were calculated via mass transfer model equation at different temperatures and different condition of extractions. According to the results (Table 2), it was seen that the diffusion coefficient increased with the increase in temperature and the effective diffusion coefficients were higher than the molecular diffusion coefficients. These results confirmed the literature knowledge explained above, once more.
In this study, data given in Table 1 were entered to the proposed design in the Design-Expert program and statistical tests were applied to each of the proposed functions. The model with the highest regression coefficient and the lowest lack of fit was chosen as the best predicted function for the response surface. For the proposed third-order model, these values were 0.9991 and 0.4027 , respectively. The predicted $R^{2}$ value was acceptable, since the actual and calculated data have acceptable level of appropriateness. Statistical analyzes are given in the Design Expert program and given in Table 3 for the reduced cubic model in the ANOVA table. A stands for solvent volume, B temperature and $\mathrm{C}$ extraction time. As the $\mathrm{F}$ value increases and the $\mathrm{p}$ value decreases, the effect of this parameter is increased. The most effective single parameter is temperature and the most effective binary parameter is time and temperature.

Table 3. ANOVA Table

\begin{tabular}{|c|c|c|c|c|c|c|}
\hline \multicolumn{7}{|c|}{ ANOVA for Response Surface Reduced Cubic model } \\
\hline \multicolumn{7}{|c|}{ Analysis of variance table [Partial sum of squares - Type III] } \\
\hline & Sum of & & Mean & $\mathrm{F}$ & p-value & \\
\hline Source & Squares & df & Square & Value & Prob $>\mathrm{F}$ & \\
\hline Model & $4.755 \mathrm{E}+006$ & 12 & $3.963 \mathrm{E}+005$ & 1362.65 & 0.0007 & significant \\
\hline A-Solvent volume & $3.535 \mathrm{E}+005$ & 1 & $3.535 \mathrm{E}+005$ & 1215.41 & 0.0008 & \\
\hline B-Temperature & $2.119 \mathrm{E}+006$ & 1 & $2.119 \mathrm{E}+006$ & 7286.75 & 0.0001 & \\
\hline C-Time & $1.693 \mathrm{E}+005$ & 1 & $1.693 \mathrm{E}+005$ & 582.33 & 0.0017 & \\
\hline $\mathrm{AB}$ & 26264,08 & 1 & 26264.08 & 90.31 & 0.0109 & \\
\hline $\mathrm{AC}$ & 55.76 & 1 & 55.76 & 0.19 & 0.7042 & \\
\hline $\mathrm{BC}$ & $3.147 \mathrm{E}+005$ & 1 & $3.147 \mathrm{E}+005$ & 1082,30 & 0.0009 & \\
\hline $\mathrm{A}^{2}$ & $5.206 \mathrm{E}+005$ & 1 & $5.206 \mathrm{E}+005$ & 1790.05 & 0.0006 & \\
\hline $\mathrm{B}^{2}$ & $4.416 \mathrm{E}+005$ & 1 & $4.416 \mathrm{E}+005$ & 1518.52 & 0.0007 & \\
\hline$C^{2}$ & 5206.23 & 1 & 5206.23 & 17.90 & 0.0516 & \\
\hline $\mathrm{ABC}$ & 0.000 & 0 & & & & \\
\hline $\mathrm{A}^{2} \mathrm{~B}$ & $2.450 \mathrm{E}+005$ & 1 & $2.450 \mathrm{E}+005$ & 842.8 & 0.0012 & \\
\hline $\mathrm{A}^{2} \mathrm{C}$ & $3.300 \mathrm{E}+005$ & 1 & $3.300 \mathrm{E}+005$ & 1134.63 & 0.0009 & \\
\hline $\mathrm{AB}^{2}$ & $4.390 \mathrm{E}+005$ & 1 & $4.390 \mathrm{E}+005$ & 1509.53 & 0.0007 & \\
\hline Pure Error & 581.61 & 2 & 290.81 & & & \\
\hline Core Total & $4.756 \mathrm{E}+006$ & 14 & & & & \\
\hline
\end{tabular}

To investigate the effect of the parameters more clearly, three-dimensional surface graphs were plotted. As seen in the Figure 7, it was observed that the extraction yield was independent of solvent volume, but to reach the highest yield, the temperature must be at minimum value. The

effect of the volume of the solvent was lower than the effect of temperature; this observation also confirmed with lower F-value than the value for temperature given in ANOVA table. Interactive effects of time and temperature (Figure 8) showed that temperature was more effective parameter than time, and to increase the extraction yield the temperature must be set at minimum value, whatever the time used. There was no red area representing the highest yield conditions were observed in Figure 9, when the interactive effects of solvent volume and time parameters investigated. This conclusion was also declared in ANOVA table with their F-values. 
Table 4. Diffusion Coefficient Terms

\begin{tabular}{lll}
\hline $1 / \mathrm{k}$ & $1 / \mathrm{t}$ & $1 / \mathrm{k}_{2}$ \\
1.315789 & 0.022222 & 14.40922 \\
12.7551 & 0.02 & 13.71742 \\
28.08989 & 0.018182 & 15.40832 \\
\hline
\end{tabular}

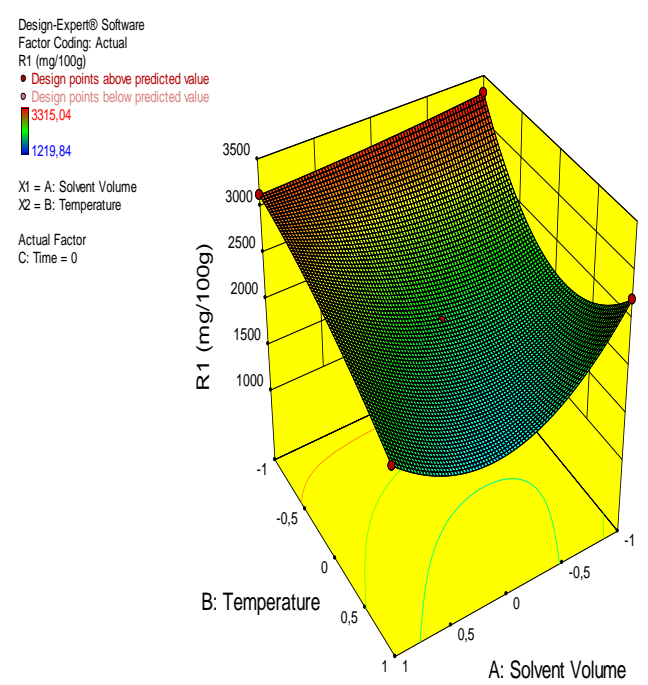

Fig 7. Response surface graph of temperature vs volume of solvent.

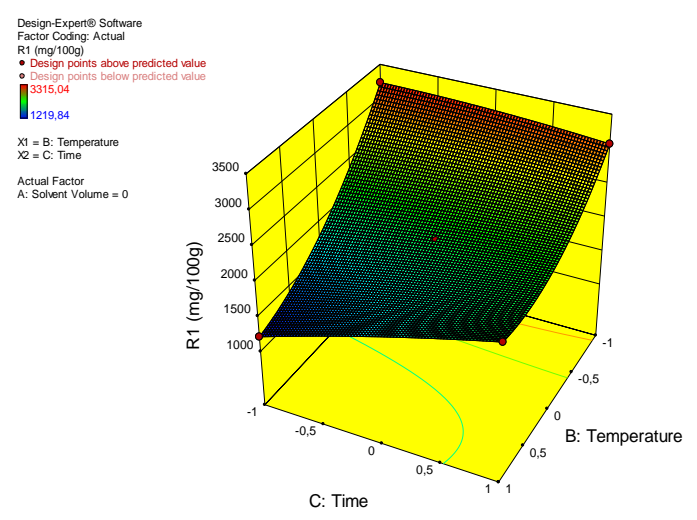

Fig 8. Response surface graph of time vs temperature.

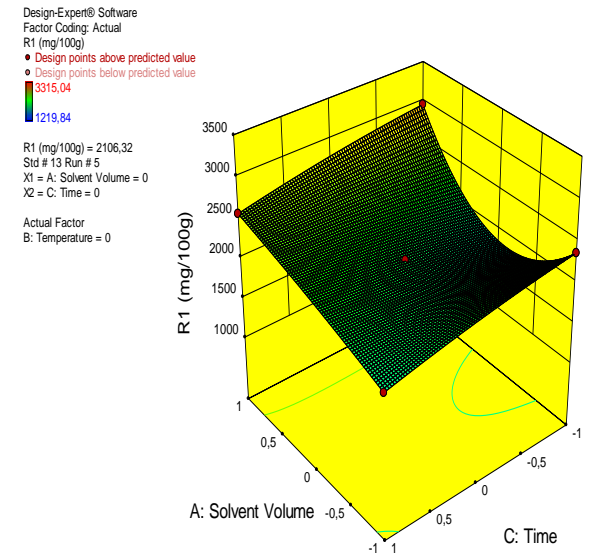

Fig 9. Response surface graph of volume of solvent vs time

\section{Conclusion}

As a result of the study, the response surface method model equation applicable for the industrial productions was found as follow:

Total amount of flavonoids (gallic acid equivalent $)=2125.67+297.26 \mathrm{~A}-727.85 \mathrm{~B}+$ $205.76 \mathrm{C}-81.03 \mathrm{AB}+3.73 \mathrm{AC}+280.51 \mathrm{BC}+$ $375.48 \mathrm{~A}^{2}+345.83 \mathrm{~B}^{2}-37.55 \mathrm{C}^{2}+350 \mathrm{~A}^{2} \mathrm{~B}-$ $406.18 \mathrm{~A}^{2} \mathrm{C}-468.5 \mathrm{AB}^{2}$

100 different numerical solutions of the mathematical model were proposed by the DesignExpert program. Production conditions of the highest amount of total flavonoid (gallic acid equivalent; $3219.67 \mathrm{mg} / 100 \mathrm{~g}$ ) were determined as $40 \mathrm{~mL}$ of ethanol usage, maximum temperature of $55^{\circ} \mathrm{C}$ and maximum mixing rate during 80 minutes. This result was also confirmed with the experimental run realized at those conditions. Additionally, Mass transfer model was found as the best model representing the experimental data at all conditions. Molecular, convective, and effective diffusion coefficients were determined at all temperatures studied. The activation energies of extraction were calculated from Table 4 . in molecular and convective transports as 54643.77 $\mathrm{J} / \mathrm{mole}$, and 6326.123J/mole, respectively.

\section{Acknowledgments}

This research has been supported by Scientific and Technological Research Council of Turkey (TUBITAK) and the authors thank for their financial support. Authors also thank chemical 
engineering Project team for their help. This study was presented in the 4th International Turkic World Conference on Chemical Sciences and Technologies (ITWCCST 2018).

\section{References}

[1] L. A. Torre, F. Bray, R. L. Siegel, J. Ferlay, J. L. Tieulent, A. Jemal, Global Cancer Statistics, Cancer Journal for Clinicians, (2012) 87-108

[2] L. Bravo, Polyphenols: Chemistry, Dietary Sources, Metabolism, and Nutritional Significance, Nutrition Reviews, 56 (1998) 317-333.

[3] M. E. Yıldırım, M. Canbal, E. Ozyuvalı, O. F. Karatas, Urological recommendations of Hadji Pasha's, a Turkish aged doctor in Anatolia, Avicenna Journal of Phytomed, 6 (2016) 502-505.

[4] A. Mukarami, H. Ashida, J. Terao, Multitargeted cancer prevention by quercetin, Cancer Letters, 269 (2008) 315325.

[5] L. Pavun, P. Durdevic, M. Jelikic-Stankov, D. Dikanovic, A. Ciric, S. UskokovicMarkovic, Spectrofluorimetric determination of quercetin in pharmaceutical dosage forms, Macedonian Journal of Chemistry and Chemical Engineering 33 (2014) 209-215.

[6] M. C. Canivenc-Lavier, M. F. Vernevaut, M. Totis, M. H. J. Siess Magdalou, M. Suschetet, Comparative effects of flavonoids and model inducers on drugmetabolizing enzymes in rat liver, Toxicology, 114 (1996) 19-27.

[7] Y. J. Moon, X. Wang, M. E. Mornis, Dietary flavonoids: effects on xenobiotic and carcinogen metabolism, Toxicol In Vitro, 20 (2006) 187-210.

[8] C. Ulger, Gallik Asit Esterlerinin Lipaz Enzimi ile Üretim Parametrelerinin İncelenmesi (Examination of Lipase Enzyme Production Parameters of Gallic Acid Esters), Graduate School of Natural and Applied Science in Ankara University, Turkey, (2016)

[9] S. Verma, A. Singh, A. Mishra, Gallic acid: molecular rival of cancer, Environmental
Toxicology and Pharmacology, 35(3) (2013) 473-485.

[10] H. Turkyılmaz, T. Kartal, S. Yiğitarslan, Optimization of lead adsorption of mordenite by response surface methodology; characterizarion and modification, Journal of Environmental Health Science and Engineering, 12(5) (2014) 1-10.

[11] F. Goktas, B. Sahin, S. Yigitarslan, Production of Sterilizing Agents from Callendula officinalis Extracts Optimized by Response Surface Technology, International Journal of Analytical Chemistry, 1 (2015) 1.

[12] M. Dastianeh, A. Vatanara, S. Fatemi, F. Sefidkon, Optimization of supercritical extraction of Pimpinella affinis Ledeb. Using response surface methodology, Journal of $\mathrm{CO}_{2}$ Utilization, 3-4 (2013) 1-6.

[13] L. Levin, C. Herrmann, V. L. Papinutti, Optimization of lignocellulolytic enzyme production by the white-rod fungus Trametes trogii in solid-state fermentation using response surface methodology, Biochemical Engineering Journal, 39 (2008) 207-214

[14] E. Hesap, S. Yigitarslan, Investigation of Microwave-assisted Extraction Conditions of Quercetin from Cinnamonum zeylaniccum with Response Surface Methodology, International Journal of Research in Medical \&Applied Sciences, 2 (2016) 1.

[15] Y. C. Cheung, K. C. Siu, J. Y. Wu, Kinetic models for ultrasound-assisted extraction of water-soluble components and polysaccharides from medicinal fungi, Food and Bioprocess Technology, 6 (2012) 26592665.

[16] J. E. Cacae, G. Mazza, Mass transfer process during extraction of phenolic compounds from milled berries, Journal of Food Engineering, 59 (2003) 379-389.

[17] E. Hesap, Modelling of Gallic Acid Diffusion: Case Study on Cinnamonum zeylaniccum, Eurasian Journal of FOOD SCIENCE AND TECHNOLOGY,2 (2018) 28-38. 